\title{
Disability, Intersectionality, and the Experiences of Doctoral Students
}

\author{
Sonia Peterson ${ }^{1}$, Toni Saia $^{1}{ }^{b}$ \\ 1 San Diego State University \\ Keywords: disability, intersectionality, higher education, doctorate, cultural identity \\ https://doi.org/10.52017/001c.31773
}

\section{Rehabilitation Counselors and Educators Journal}

Vol. 11, Issue 1, 2022

\begin{abstract}
Assuring diversity of faculty in graduate school programs continues to be a focus of practice and research because of the need to ensure inclusion for all students seeking higher education. Women, individuals with disabilities, and individuals with other traditionally underrepresented cultural group identities are all underrepresented at the doctoral level in higher education, in tenure-track, full professor faculty positions, and in administrative leadership positions such as dean and president. This study is one of the first to document how doctoral program students with disabilities, who also have other traditionally underrepresented cultural group identities, experienced the successes and challenges of earning a doctoral degree. An intersectional framework was used to explore access and inclusion at the doctoral level in academia. Four major themes-defining personal cultural identities, navigating systems and situations, resources and motivation, and leveraging lived experience as a skill set for work in a chosen field-emerged from the data. Recommendations to increase access and inclusion are offered.
\end{abstract}

Jobs that require graduate-level education are increasing in the United States (Torpey, 2019). Additionally, faculty members with doctoral-level education are required to provide instruction and leadership for the diverse body of students who will enter the workforce or continue as instructors in academia (Chronicle of Higher Education, Inc, 2021). Women, faculty of color, and faculty with disabilities are underrepresented at the doctoral level in higher education in tenure-track, full professor faculty positions, and in administrative leadership positions such as dean and president (Aiston \& Fo, 2021; Chronicle of Higher Education, Inc, 2021; Smith et al., 2012; West \& Curtis, 2006). The statistics coursework required for the successful completion of a doctoral program may present challenges for many students with traditionally underrepresented cultural group identities (TUCGI), due to limited knowledge and experience with math and research methods or difficulties with access to course materials for students with disabilities (Black et al., 2015; Darolia et al., 2020; Godfrey \& Loots, 2015; Marson et al., 2013; Moore et al., 2015). Barriers to access in the academic environment, such as a lack of mentors, microaggressions, or discrimination in classroom environments, may hinder completion of a doctoral program and deny advancement to tenured faculty and leadership positions for students with TUCGI (Damiani \& Harbour, 2015; Van Miegroet et al., 2019).

\section{Discrimination in Academia}

Over half of individuals who have disabilities are women, therefore most individuals who have a disability have an intersectional identity (Hirschmann, 2012). Many women also have an additional TUCGI based on race, ethnicity, or sexual orientation. Several current researchers have noted the impact of intersectionality on access to postsecondary education. Crenshaw (1989) first coined the term "intersectionality," which has been used to describe the phenomenon of overlapping cultural identities and related systems of oppression and discrimination. Additionally, scholars have begun relating intersectionality theory to the experience of individuals with disabilities (Hirschmann, 2012; Liasidou, 2013; Shaw et al., 2012; Warner \& Brown, 2011).

A feminist theory intersectional framework parallels concepts in the disability studies social model framework, by shifting focus from the individual to the environment when designing programs and policies to improve equity, access, and inclusion (Aune \& Kroeger, 1997; Montgomery, 2020; Oliver, 2013; Valentine, 2007). Individuals with intersectional identities, namely combinations of specific TUCGI such as being a woman, having a disability, and/or having another TUCGI, seem to be at higher risk of experiencing discrimination; they also experience discrimination in different ways and of a different quality than individuals who identify as having only one TUCGI (Hirschmann, 2012;

\footnotetext{
a slpeterson@sdsu.edu

b tsaia@sdsu.edu
} 
Liasidou, 2013; Shaw et al., 2012; Warner \& Brown, 2011). Disparities in access to higher education for individuals with disabilities are well documented (Kutscher \& Tuckwiller, 2019; Paul, 2000; S. Rao, 2004; Raue \& Lewis, 2011; Yssel et al., 2016). Race and socio-economic status (SES) play a large part in which students are diagnosed with a disability and the types of accommodations these students receive under an Individualized Educational Plan (IEP) in elementary and secondary school (Scarborough \& McCrae, 2010; Skiba et al., 2005). A disability label compounds the effects of race and SES, and students who identify as members of all three of these groups face multiple barriers to success after high school, including access to higher education (Balcazar et al., 2012).

Gender, race, disability status, and SES all impact access to higher education at the graduate level, and students with TUCGI participate in science/technology/engineering/math (STEM) degree programs in fewer numbers and are less represented in the teaching faculty in these programs (Chronicle of Higher Education, Inc, 2021; Van Miegroet et al., 2019). Students with disabilities and students with other TUCGI are underrepresented at the doctoral level in higher education (Kim, 2013; Montgomery, 2020; Van Miegroet et al., 2019). Furthermore, doctoral graduates with TUCGI are underrepresented in faculty positions in higher education (Smith et al., 2012). Although women represent more than half of doctoral graduates since 2006, women continue to be underrepresented in tenure-track and full professor positions (Nicholson, 2020; West \& Curtis, 2006). Although there has been some progress in the last 30 years, women and individuals with other TUCGI who hold doctoral degrees continue to be substantially underrepresented in administrative leadership positions in higher education, such as in positions of dean and president (King \& Gomez, 2008; Nicholson, 2020).

\section{The Present Study}

This study is one of the first to document how doctoral program students with disabilities who have additional TUCGI experienced the successes and challenges of earning a doctoral degree. Their experiences shed light on challenges and resources unique to individuals with disabilities who identify as having additional intersecting TUCGI. This information can be used to increase access in academic settings and to develop effective resources and inclusive academic environments for individuals with disabilities who have additional TUCGI. As such, the study was specifically designed to address the following research questions:

1. What was the motivation to pursue a doctoral degree?

2. What were the barriers and challenges that these individuals faced in completing their graduate programs?

3. What resources were used to complete doctoral program requirements successfully?

\section{Method}

In qualitative study, research questions are established and data collection proceeds systematically, yet flexibly, making it a powerful tool for exploring the experiences of small populations of individuals with a common experience. In this study, the principal investigator (PI; first author) began collecting data with knowledge about disability, intersectional identities, and institutional environments, but without an understanding of (a) the experiences of students with disabilities who have additional TUCGI who completed a doctoral degree program, or (b) what resources these individuals used to navigate the challenges inherent in completing a doctoral degree. Individual interviews were used to gain information about these experiences.

\section{Participants}

The study included nine individuals. The nine participants shared that they were working or studying in a variety of settings, represented a range of individuals with both mental and physical disability identities/impairments, and graduated from their doctoral program as far back as 1995 . At the time of publication, all participants had earned their doctoral degrees. Some individuals shared they identified as having more than one cultural identity, disability identity/ impairment, and/or current work situation (see Table 1).

\section{Maintaining Participant Confidentiality}

The number of individuals with disabilities who also identify as having another TUCGI and who obtain a doctoral degree is relatively small. Academic departments and professional organizations also present relatively small numbers. Members of academia are easily familiar with each other through their work in research, teaching, and service positions. The PI purposely chose not to describe each individual participant in specific detail, which would likely make some of the participants identifiable. Therefore, the findings and themes have been reported in a general way and pronouns have been kept neutral whenever possible to maintain the confidentiality of all the participants.

\section{Instruments}

The interview protocol used was comprised of eight main questions and prompts for follow-up questions to each of the eight questions. Questions were derived from published literature on intersectionality, published studies on the experiences of graduate students with disabilities, and the PI's previous research experience. Question content included cultural identity, challenges in doctoral programs, and how the participant was using their lived experience in their current employment. Interview questions were designed to collect information about the participants' experiences as they navigated their doctoral programs of study-especially their experiences completing required statistics and research methodology coursework. The PI conducted all the interviews and ensured all questions were answered by the end of each interview.

\section{Design: Phenomenology}

Phenomenology is a qualitative research approach that guides the exploration of the lived experience of individuals (Creswell \& Poth, 2016). Rather than comparing the responses of participants to existing data, standards, and 
Table 1. Participant Characteristics $(\mathrm{N}=9)$

\begin{tabular}{|c|c|c|}
\hline & $\mathbf{n}$ & $\%$ \\
\hline \multicolumn{3}{|l|}{ Gender } \\
\hline Woman & 5 & 55.6 \\
\hline Man & 4 & 44.4 \\
\hline \multicolumn{3}{|l|}{ Sexual orientation } \\
\hline Lesbian & 1 & 11.1 \\
\hline Gay man & 4 & 44.4 \\
\hline Straight/heterosexual & 4 & 44.4 \\
\hline \multicolumn{3}{|l|}{ Race/ethnicity } \\
\hline African-American/Black & 1 & 11.1 \\
\hline Latino & 1 & 11.1 \\
\hline Asian-American & 1 & 11.1 \\
\hline Italian-American & 1 & 11.1 \\
\hline White/Caucasian & 5 & 55.6 \\
\hline \multicolumn{3}{|l|}{ Other identities/cultural groups } \\
\hline Veteran & 1 & 11.1 \\
\hline "Grew up middle class" & 1 & 11.1 \\
\hline "Grew up Protestant" & 1 & 11.1 \\
\hline Active in Alcoholics Anonymous & 3 & 33.3 \\
\hline \multicolumn{3}{|l|}{ Disability identity/impairment } \\
\hline ADHD & 2 & 22.2 \\
\hline Deaf & 1 & 11.1 \\
\hline Visually impaired & 1 & 11.1 \\
\hline Wheelchair user & 1 & 11.1 \\
\hline Rheumatoid arthritis & 1 & 11.1 \\
\hline Bipolar disorder & 2 & 22.2 \\
\hline HIV/AIDS & 1 & 11.1 \\
\hline Recovering alcoholic & 3 & 33.3 \\
\hline \multicolumn{3}{|l|}{ Area of doctoral study } \\
\hline Psychology & 1 & 11.1 \\
\hline Engineering & 1 & 11.1 \\
\hline Rehabilitation Counselor Education & 2 & 22.2 \\
\hline Special Education & 1 & 11.1 \\
\hline International and Multicultural Education & 1 & 11.1 \\
\hline Gifted, Creative, and Talented Studies & 1 & 11.1 \\
\hline Business Management & 2 & 22.2 \\
\hline \multicolumn{3}{|l|}{ Languages } \\
\hline Bilingual Spanish-English & 1 & 11.1 \\
\hline Multilingual & 1 & 11.1 \\
\hline ASL & 1 & 11.1 \\
\hline English & 6 & 66.7 \\
\hline \multicolumn{3}{|l|}{ Traditional or on-line program } \\
\hline Traditional campus-based program & 7 & 77.8 \\
\hline Primarily online program & 2 & 22.2 \\
\hline \multicolumn{3}{|l|}{ Current work and/or student status } \\
\hline Tenured professor & 2 & 22.2 \\
\hline Research professor & 1 & 11.1 \\
\hline Assistant professor & 1 & 11.1 \\
\hline Instructional faculty & 1 & 11.1 \\
\hline
\end{tabular}




\begin{tabular}{lcc}
\hline & $\mathbf{n}$ & $\%$ \\
\hline Manager with federal agency & 1 & 11.1 \\
Federal employee & 1 & 11.1 \\
Current doctoral student ABD & 2 & 22.2 \\
Post-doctoral student & 2 & 22.2 \\
Age (in years) & Range $=25-62$ \\
Year graduated & SD $=45$ & Range $=12.7$ \\
& $\mathrm{M}=2010$ & \\
\hline
\end{tabular}

norms, the researcher seeks to understand how situations appear to participants and how these events, people, and experiences impact the person's choices and behaviors (Glesne, 2015). A phenomenological approach was selected to focus on understanding the meaning that obtaining a doctoral degree had for participants, and grounded theory was useful to find out how these individuals navigated the process of earning their doctoral degree (Charmaz, 2014; Creswell \& Poth, 2016). This phenomenological study included individual case studies. Cross-case analysis was utilized to understand how intersectional identities shaped the experiences of each of the participants while completing their doctoral degrees.

\section{Procedure}

A convenience sample was used. The PI emailed faculty members at higher education institutions and other colleagues they knew personally or from professional organizations to participate in the study and/or recruit participants. Individuals were included who fit the following criteria: (a) graduate of a doctoral program, or a doctoral student who had completed all but their dissertation (ABD) towards their degree and was within one year of completing their degree; (b) identified as having a disability; (c) identified as having an additional TUCGI; and (d) attended elementary school and secondary school in the United States.

\section{Interviews}

Structured interviews were conducted with each of the nine participants by telephone and lasted 40-60 minutes each. The open-ended interview questions were designed for the participants to reconstruct their experiences with their doctoral program and to reflect on the meaning the participant attributed to their experiences (Seidman, 2013). The participants were asked to assess how they viewed themselves culturally, and in which communities or groups they were active. They were also asked to describe challenges and resources they encountered while completing their doctoral degrees. The participants were prompted to consider aspects of their program, such as coursework; their peers, faculty, friends, family, and spouses; research methodology/statistics classes; completing their dissertation; accessing financial resources; supervision; working; finding housing; and other aspects of their experiences. Participants had the opportunity to share their motivation for pursuing a doctoral degree, feelings about how their personal experiences influenced their contributions to their field, and any other information they wanted to be included in the study. All interviews were audio recorded and transcribed verbatim, omitting any identifying information.

\section{Data Analysis}

Transcripts from the nine individual interviews comprised 108 single-spaced pages. NVivo software was used to facilitate qualitative analysis. The PI conducted member checking by providing each participant with a copy of the transcript from their individual interview so they could assess whether the information shared was an accurate representation of their experience. Using editing analysis style, the interviews were interpreted for meaningful fragments. Taxonomic and emotions coding techniques were utilized to capture patterns in speech, behavior, and emotions that added insights into the experiences of the participants (Glesne, 2015). The fragments were reviewed and developed into categorical themes as they emerged. Next, the themes were cross-tabulated and matched to derive codes for further analysis and merged into more transcending themes. Final coding schemes were used to sort themes into patterns that were structured and interpreted. The themes were compared to the existing literature on the experiences of doctoral degree graduates with disabilities, doctoral degree graduates with TUCGI, and intersectionality theory. The PI searched for additional themes that emerged in addition to the themes established by the structured questions (Hatch, 2002). The interview notes were reviewed multiple times, and the PI confirmed the gathered data supported the patterns and themes that were established.

\section{Avoiding Researcher Bias}

Scholars have noted that one of the most important ways to increase validity in qualitative studies is to actively utilize techniques to minimize researcher bias (Maxwell, 2012; Seidman, 2013). The PI reflected extensively on their subjectivity on this topic throughout the study, and actively engaged in examining the objectiveness of the findings (Glesne, 2015). During the study, the PI was completing a doctoral program, and identifies as Caucasian, lesbian, and in recovery from substance use disorder and other mental health disabilities. The PI had also worked in the field of vocational rehabilitation for over twenty years and had many personal and professional experiences with individuals with disabilities and individuals with intersectional identities. 
The PI naturally had biases and expectations regarding the topic they worked to carefully keep in check, as much as possible.

This study and the methods were designed to incorporate techniques to avoid researcher bias. The open-ended interview questions were designed to elicit significant, indepth retrospective responses of individual participant experiences (Seidman, 2013). Member checking techniques, as outlined above, were utilized. The PI utilized ongoing journaling and consultation while conducting the entire study, and used an auditor to review the transcripts and assess the material for their own identification of themes, which were compared the PI's, to maintain the integrity of the study (Glesne, 2015).

\section{Results}

From the data, themes emerged regarding common challenges encountered and strategies the participants used to navigate their doctoral programs successfully. Data analysis revealed four major themes: (a) defining personal cultural identities, (b) navigating systems and situations, (c) identifying resources and motivation, and (d) leveraging lived experience as a skill set for work in a chosen field emerged from the data. Additional subthemes included navigating family relationships under the second theme, and financing the doctoral program, social supports, and motivation under the third theme.

\section{Defining Personal Cultural Identities}

All nine participants discussed experiences related to identity development on personal, academic, and professional levels. All participants further discussed experiences related to their identities as a person with one or more disabilities, their experiences as members of other cultural groups, and the impact of their cultural identity on their doctoral path.

Specifically exploring intersectional identities in relation to the experience of earning a doctoral degree was the PI's interest, and not all participants shared at the outset that they felt a strong affiliation to any one particular identity or identities. Two participants articulated strongly that they considered themselves an individual. When asked about the cultural identities that resonated with them, one participant responded, "I consider myself an individual by the name of [participant's name].” The other of the two participants shared, "I've been trying to figure out how to respond to that...there are so many factors...it's a difficult question to answer," then laughing asked, "What day of the week is it?" This participant, who had recently graduated, clearly shared why it can be detrimental to label singular identities or individuals as marginalized or underrepresented. The individual stated,

I think everybody makes unique contributions because of their experiences. I think it's unfortunate that we tend to frame members of marginalized populations as the being the only ones who come with those unique experiences. Because I think it ends up as being an "othering" thing.

A participant who has been a faculty member in her field for a number of years, shared that she felt her gender was more of a barrier in career recognition and advancement than any of her other identities, which included living with a disability:

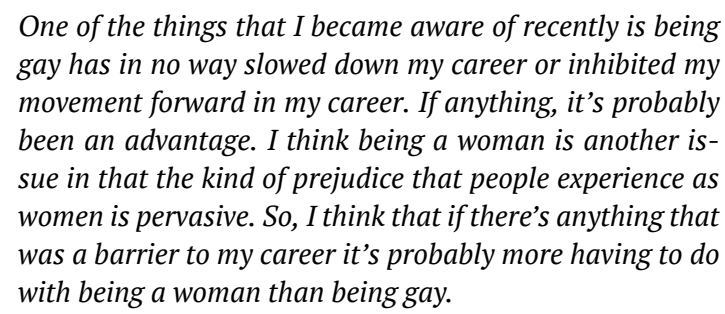

However, another participant in the same field of education shared that she felt her gender did not impact her career or access in any negative way: "You know, education-it's not like the sciences where you're kind of having to fight for your gender, so, I don't really feel like my gender has an impact.”

Another participant, who was completing dissertation requirements, shared they felt their identity as an African American and the resiliency they developed as being a member of this specific underrepresented group was an asset in navigating the process of earning a doctoral degree and furthering their career goals:
I believe that growing up in an era where African Amer- icans did have to know twice as much and work twice as hard has impacted me. There's a resiliency I believe that I developed, so it was probably an advantage of being a part of one of those groups and the effort that it takes to be seen the same.

All participants spoke extensively at some point during the interview about the strengths gained from each of their unique cultural identities, and how these identities contributed to their resilience to persevere through their doctoral programs. The participants identified strongly with their Black, Latino, Asian, Alcoholics Anonymous, queer, veteran, academic, and/or disability cultures and communities.

\section{Navigating Systems and Situations}

The participants shared a wealth of experiences illustrating various challenges with systems and situations. These included experiences in the academic environment, such as navigating relationships with faculty, navigating required statistics coursework, and securing accommodations. An important subtheme of navigating relationships with family members also emerged from the data.

One participant in this study, who had earned a STEMrelated doctoral degree, clearly articulated that navigating the doctoral degree experience was quite different for an individual with a significant disability, who was also experiencing barriers as the result of other identities:

Grad school is hard no matter who you are and what you're studying. It's supposed to be hard because it's a place where you grow and study. The largest challenge for me has been filtering out if I am having difficulties is it because grad school is hard or are you having challenges because you are $x, y$, or $z$. So, it's really hard to separate that, and it's really hard to recognize that. Especially in STEM fields-there's a culture of, of course it's hard, and 
you have to be tough and use more intelligence and hard work to be better at it. That's the solution. The problem is not that you are Black or queer or whatever. The problem is something that you should be able to fix or figure out. So that was my first challenge-figuring out that there were challenges that were not of the "you're in grad school it's supposed to be hard" variety.

Forms of bullying from faculty members were described by two of the participants regarding their requests for accommodations in statistics courses. The participant who had a visual impairment shared their experience of asking for notes before class and for enlarged copies of the data that would be used in class in a statistics course, and the instructor initially "flat out" told them "no." The participant shared that they persisted, went to class, and on the fourth day of class, the instructor slammed down the materials in a larger format in front of the participant, but did not say anything to them. The participant shared, "I had to prove to her I wasn't going away and I was going to get the work done. So, I would say that was probably my biggest Ph.D. struggle". The participant shared they got through the class with a lot of assistance from classmates, which included studying together and trading the use of their washing machine or babysitting services in exchange for notetaking services from their classmates.

A Deaf participant shared that they requested a captioner as an accommodation in a statistics class, and the captioner was quite good. However, the captioner had to keep asking the instructor to please speak more clearly, repeat words, and repeat slides during the lectures so they could properly caption the information being shared:

\footnotetext{
Halfway through the course I said (to the instructor), "can I just do an independent research project on this topic, and if I turn it in and it works will you give me credit for it?" And I think at that point he was sick of me so he said, "yes". So, I skipped classes for the remainder of the semester, learned statistics on my own, did the project, and got an A+ in the class, but, that's not the way it should be.
}

\section{Navigating Family Relationships}

One participant clearly expressed challenges resulting from the difficulties of navigating the various roles and expectations that come with living as a woman with more than one cultural identity:

I remember my grandmother's reaction when I got accepted into my program. "Oh good, it has always been our dream to have a doctor in the family." Her second comment was, "nobody will want to marry a woman who has more education than them". When they found out that I was disabled that was one of her first worries, apparently. Who was going to want to marry this disabled kid? And now, I'm making it even harder by going to get a Ph.D.

This participant further explained the importance of maintaining family relationships and the immense support she felt from this close network of immediate and extended family.

Navigating family relationships was a significant aspect of successfully navigating the doctoral program shared by most of the participants. One participant shared they ex- perienced the death of their father two months before they started their doctoral program. Another participant shared that their spouse had a disability, and the need to care for their spouse at times put stress on their ability to focus on their doctoral program. Two participants shared they were living in different cities from their spouses during their program-one of whom was working out of the country while completing courses online.

\section{Identifying Resources and Motivation}

Despite challenges navigating systems and relationships, all nine participants shared rich examples of resources and emotional support in their academic experiences, as well as strong motivation to complete a doctorate degree. Resources included mentors, supportive faculty, family members, peers, financial support, and support from communities related to cultural identities. Motivations included wanting to teach and wanting the recognition that comes with earning a doctorate.

All participants stressed the importance of mentorship as a helpful resource in their programs. A participant who had graduated recently shared ways her advisor was supportive specifically around her disability:
My advisor asked how she could support me, validated my experience, and respected my autonomy and privacy by asking if there was anything she wanted me to share with our faculty regarding my struggle. She also asked if I would be interested in talking to another student she knows in the college with (same disability) for someone to talk about their experience being a relatively young Ph.D. student and having this condition and change in ability level. She has checked with me about how I'm doing and supports and advocates for me when I'm struggling.

Another participant shared a detailed example of how they were able to connect with a network of other Deaf faculty through a mentor not in their field who was willing to reach out to the student:

There was another professor in my university completely outside of my field who was also Deaf, and she emailed me and said, "Would you like to go get coffee sometime and talk about strategies for teaching in a classroom?" So, I sat down and I talked with her and I went, "Holy crap! I've never met a Deaf faculty member!"

Participants also shared there were supportive faculty that they were able to establish relationships with during their programs. A participant who was not treated well initially by a statistics professor later stated that the instructor was very helpful to them when they needed assistance with their dissertation study. Another, who completed their Ph.D. several years ago, shared a clear example of a supportive dissertation chair:

My chair for my master's thesis and my doctoral dissertation was the same man. I called him all the time. He'd work through different issues with my work and process or whatever. I think that's part of what made (university) so interesting. You know it's very personalized to the student...they want you to succeed. 
Another participant shared that, overall, their advisor and other faculty in their department were supportive and encouraging towards their doctoral students. The environment of the department was described as welcoming, collaborative, and inclusive:

The graduate students and the professors worked very closely together. Really with all the professors in our department there was very much an open-door policy. It wasn't uncommon to walk by the graduate student offices and see a professor who had just popped in and sat down and started chatting with the grad student. So, it was an incredibly supportive environment. The friendships that I made within my cohort and with those students that were before me and after me, are friendships and connections that I will have for life.

\section{Financing the Doctoral Program}

All participants shared about the various financial resources they used to complete their programs. The veteran participant used his GI Bill, others received assistantships, and one used a government grant. Three had spouses that contributed resources and emotional support. One used student loans and work income to fund their online doctoral program coursework while they worked out of the country.

\section{Social Supports}

The participants in this study shared examples of a rich variety of social supports that included supportive relationships found in service work related to their cultural and professional identities. One participant stated they were partnering with another faculty member to reach out to disadvantaged youth in their large urban community to provide internship opportunities in education for graduate students in their departments. This participant shared that they were highly involved with faculty during their doctoral program in similar types of projects. Another participant shared that during their program they had a very supportive partner, now spouse, and friendship group that provided the emotional support they needed to progress through the program. They had worked in their field before returning to school to pursue the doctorate degree. They were currently active professionally in community groups, professional organizations, and in conducting research with other professionals in their field.

Other participants shared examples of connections between social support groups and personal and professional service work in their communities. The three participants who identified as being sober many years through Alcoholics Anonymous (AA) shared that they went to AA meetings during their programs. They shared that the AA community was a big support during their doctoral programs, and they had continued to be active in AA, as well as other community organizations.

\section{Motivation}

Participants shared that their primary motivations to complete a doctoral degree were related to research, teaching, being a role model, and earning the recognition that comes with a doctoral degree. All participants shared that the main reason for pursuing a doctoral degree was to teach or do research, or both. One shared that witnessing an ineffective teacher for youth with disabilities while they were working in a school after earning their master's degree was a big motivation to go back into academia, to work with students who would be going out into the field to teach. Most participants shared they had worked in their field after completing a master's degree, and wanted the opportunity to have an impact on students who would be going out into their fields to teach and work as a professor and mentor.

One participant shared that, even though they had significant struggles completing their doctoral program several years ago, they had been highly successful in their academic career and felt good about the work they were doing because of the opportunities that the degree had afforded them. They shared, "I think on one level I love what I do, so work and play is kind of combined. So, when I go to prepare a lecture I think, 'oh this is such an exciting concept. I can't wait to teach it'."

Other participants shared motivations for doing research that were tied to their specific interest areas. One recent graduate stated he wanted to teach and continue to examine military policy around LGBTQ+ rights, "to do research in fields that there needs to be more research done in. and I think a lot of my future research will be military just because I've had the experience."

Another participant shared he felt he needed to go to the highest level in academia to realize his full potential and to be a role model for other family members:
I have cousins who I kind of see more as nieces and a nephew that have only seen kind of one side of life, and our parents-their mother and my mother went to junior college but never completed their undergrad work, and I wanted them to see that someone in our family could con- tinue and achieve post graduate level work, and to be able to explain to them that they're no different than myself, and to continue on regardless of what's going on around them.

A participant also shared specific motivations related to their status as a role model for others with visual impairments. One participant who was completing dissertation requirements articulated clearly the importance of achieving what society does not support or expect for individuals with disabilities:

I thought my Ph.D. would open more doors. But I'm not gonna lie-the second motivation, people don't expect me to go get a Ph.D. Society has low expectations for me because I am disabled. So that kind of fueled my fire to go get one. Because people with disabilities are underrepresented in higher education.

A doctoral degree is a measure of success and one participant, who wanted to use the degree to teach, also shared they were motivated to reach the goal of obtaining the highest degree possible in academia. "The high achiever in me wanted to achieve a Ph.D. The perfectionist in me wanted a Ph.D. because it is an indicator of success." 


\section{Leveraging Lived Experience as a Skill Set}

The final common theme found in the experiences of the participants was the possession of rich life experiences that could be shared with students and colleagues. All described ways in which they were able to use their personal experiences in their work. For example, one participant was teaching graduate students who were earning their teaching certificates. They stated they were able to share while teaching classes such personal experiences in managing their own disability, their experiences as a K-12 instructor, and information about special education that their students did not necessarily receive anywhere else in their program. Another had focused research efforts on interventions to make math education more accessible to youth with visual impairments.

One participant shared an especially rich history of service in various capacities in relation to several aspects of their intersectional identities:

\section{I taught for almost 18 years in public schools. And almost all the schools I taught in were in the ghettos and barrios of (major urban areas on the west coast) so I always worked with underserved people and children. I guess it really did help me define my beliefs and gave me strategies to work with up-and-coming teachers}

This participant had been mentoring and teaching students earning their teaching certificates at a state university in a large urban area on the west coast for several years.

One participant shared how they had contributed to education in psychiatric rehabilitation during their career:

\section{In my career, I worked with a wide range of different types of disabilities and some of the people I worked with had psychiatric disabilities, some had developmental disabili- ties, I also worked with a number of people who were blind and visually impaired over the years. I really turned my attention to psychiatric disability as it impacted me...as I became more interested in it as a phenomenon, now all my research and all my teaching is focused on psychiatric re- habilitation.}

Participants also shared about how their own doctoral experiences had influenced the way in which they supported their students pursuing this degree:

I know as a professor I am a whole lot more attentive to my doctoral students than anyone ever was to me as a student. And that's all based on my own bad experience with it. And hopefully I'm able to help them make better choices. Because you don't know what you don't know.

One participant, who was completing dissertation requirements, observed they had an ability to act as an advocate and educator about disability, intersectional identities, and access to course material within their program because of the life experience they brought to their doctoral program:

To be honest I feel like I'm giving my professors education on disability and having them examine what they think they know. Also, I'm providing an opportunity to put universal design to the test because before they see me they don't think they need to do anything, so I kind of force them to create a more inclusive environment. I feel like professors don't think about the intersectionality of identities. For example, being a disabled woman.

Another participant, who was working in the private sector and completing dissertation requirements, shared how their own personal experiences had influenced their work in advocating for workers as a manager. "I believe that I contributed because of my life experience, and it has to do with the voices of underrepresented groups being heard." This participant shared a story about how they were able to impact policy to assist workers in getting fair compensation for living expenses while living abroad and working for the U.S. Military.

\section{Discussion}

The findings lend support to earlier research describing identity development, benefits of Universal Design for Learning (UDL) for students with disabilities, the importance of mentors, navigating family relationships, and using lived experience as a skill set. The experiences shared by the participants in this study illustrated ways in which they felt a sense of inclusion and sustained the personal motivation to persevere through a doctoral program. At the same time, their experiences also illustrated areas where strategies for access and inclusion need to be further developed. Stories emerged from the interviews that clearly captured the participants' skills in navigating systems and situations, their supports and motivation to complete doctoral degree programs, and the results of being able to leverage their lived experience as a skill set.

\section{Identity is Fluid}

Azmitia and Thomas (2015) stated that one of the emerging trends in the social and behavioral sciences is the concept of intersectionality as it relates to the development of self and identity. The experiences of these participants illustrate that identity is fluid and depends on context (Valentine, 2007). Although participants may have had similar experiences regarding access, these experiences were not dependent on their specific identities or personal characteristics. For example, the participants who identified as women did not always view this aspect of their identity in the same way regarding their experiences of inclusion in an academic environment. This supports what Museus and Griffin (2011) advocated for in their recommendations to incorporate an intersectional lens in educational research, rather than utilizing singular categories of cultural identities. Using strategies that incorporate intersectional and socially inclusive frameworks when seeking to increase access shifts the focus on the environment and the responsibility to administrators and institutions. By seeking to increase access and inclusion in the academic environment, doctoral programs have the potential to welcome a wider diversity of students.

\section{Universal Design for Learning}

There is a growing body of evidence-based UDL techniques in math and science coursework at the $\mathrm{K}-12$ level $(\mathrm{K}$. 
Rao et al., 2014). However, research is limited on specific strategies for math and science instruction for students with disabilities at the postsecondary education level, and even less literature exists that discusses specific strategies for statistics coursework instruction for students with disabilities at the graduate level (Black et al., 2014, 2015; CAST, 2021; Godfrey \& Loots, 2015; Marson et al., 2013). Graduate students with disabilities and/or with other TUCGI may not be encouraged to pursue or participate in upper-level research methodology and statistics coursework if instructors are not knowledgeable about modifications that can be utilized in course material and instruction to increase access to the information offered in these types of classes.

One participant specifically shared recommendations for UDL techniques that can be incorporated into statistics coursework to increase access and inclusion, and all participants shared techniques they utilized to complete their statistics coursework successfully that included elements of UDL. One aspect of UDL is to provide students with multiple means of engagement. This enhances the "affective network" in learning, assisting students to develop self-determination and pride in accomplishment, and increases the degree to which they feel connected to their learning (CAST, 2021). Several participants noted the benefits of forming study groups for their statistics coursework. Some sought out faculty or statistics resource centers on their campus for further help with connecting their specific research interests with the statistical analyses appropriate for their interests.

\section{Navigating Relationships}

The responses from the participants related to navigating relationships with faculty, navigating required statistics coursework, securing accommodations, and navigating relationships with family members supported the existing literature. Authors have discussed this type of navigation as a learning process (Jairam \& Kahl, 2012; Rockinson-Szapkiw \& Spaulding, 2014). The participants with significant disabilities shared experiences that illustrated well the barriers to access that exist in statistics coursework. Their experiences showed that the problems they experienced receiving accommodations were not associated with their requests at their disability resource centers, but rather were difficulties and bullying they experienced with instructors who were not open to, knowledgeable about, or experienced with providing the requested accommodations in their classes. Researchers found that $74 \%$ of the graduate students surveyed shared they felt they had experienced some form of bullying from faculty members during their graduate student experience (Martin et al., 2015). Some of the experiences shared by the participants around seeking accommodations in their statistics coursework are examples of what Martin et al. (2015) described as belittling, discrimination, and harassment.

Research exists on the experiences of youth with disabilities in the transition from high school to undergraduatelevel higher education (Test et al., 2009). Specific research on access to graduate-level statistics coursework for all students including those with disabilities is scarce, but there is a growing body of research on access to STEM coursework in K-12 education and access to higher education in general (Black et al., 2014, 2015; CAST, 2021; Mole, 2013; K. Rao et al., 2014). Researchers have explored extensively the attitudinal barriers students with disabilities experience in undergraduate-level higher education, which has included discussion of the willingness of faculty to provide accommodations in their classes (S. Rao, 2004).

The difficulties living as a woman with more than one TUCGI shared by one of the participants supported what was found in the literature (Liasidou, 2013). The way that one woman participant stayed in communication and navigated the relationships in her large extended family mirrored the recommendations that Jairam and Kahl (2012) discussed in their study of the importance of social supports during the process of earning a doctoral degree. These authors recommended explaining the process to family members throughout the doctoral program so they understand the process and can continue to be supportive in ways that are helpful.

\section{Mentors, Social Supports, and Service}

Mentors and supportive faculty have been important for graduate students with disabilities (Collins, 2015; Damiani \& Harbour, 2015). Jairam and Kahl (2012) documented examples of social supports that were found to be helpful to doctoral students in completing their degrees. They found the social supports of academic friends, supportive family members, and supportive faculty were crucial in helping doctoral students to cope with the stress of completing their degrees. Encouraging doctoral students to make connections with other faculty, other students with similar interests, and other resources on campus can assist with developing an interest in statistics and an ability to increase their research skills, rather than viewing statistics classes as something difficult and foreign that needs to be endured as part of their program.

Gaining support and encouragement from mentors was another important, common experience shared by the participants. Again, the support of mentors further enhances a student's connection to their learning experiences during their doctoral program and increases connections to other experts in their fields. For students living with significant disabilities, it did not seem to matter that a mentor was somebody specifically from their field. The Deaf participant shared that it was very important to them to connect with another Deaf faculty person, even though they were in different fields, because this helped them with practical issues around communication in classroom instruction and to gain social support of other faculty in similar situations.

Galanter et al. (2013) documented the importance of service as a means to stay connected with others, and support recovery from substance use disorders. One participant was reaching out to other veterans who were in treatment for substance use disorders. One stated he worked with other recovering alcoholics as a sponsor, and also did volunteer work with non-profit groups that serve gay men in the community. One participant shared he was a vice president of a non-profit that served men living with HIV/AIDS during his doctoral program; his work with this group provided him 
with an opportunity to conduct research for his dissertation study. These examples not only illustrate the importance of social supports to help with personal stress, but they are examples of how these types of relationships can assist with finding meaningful research and other professional opportunities in the community-opportunities that might not be found if limited to faculty or other students in their immediate academic programs and that might not provide the social and professional connections that are most meaningful.

\section{Lived Experience}

Lived experience with a disability can provide one with an exceptional professional skill set, and professionals with lived experience are sought out in both work and academic settings (Happell et al., 2015; Van Manen, 2015). All participants shared ways in which their lived experience was impacting their professional work in a positive way.

The opportunity to be a role model for others with disabilities can have significant impacts. The employment rate of people with disabilities is approximately $18 \%$, compared to non-disabled individuals of whom over $62 \%$ are employed (U.S. Bureau of Labor Statistics, 2021). Persevering through a graduate program can result in a significant financial gain for a person with a disability. A graduate degree opens up more career opportunities at higher salaries (Torpey, 2019). Serving as a role model in this capacity can provide others with the motivation to pursue higher academic work and reach higher career goals.

\section{Recommendations}

It is imperative that graduate students with disabilities be provided with opportunities to develop relationships with mentors and other supportive faculty. Overall, barriers to access, as described by the participants, had more to do with environments and less to do with specific characteristics, knowledge, aptitudes, or identities. It would appear from the experiences shared in this study that increasing education in UDL principles and techniques for faculty and administrators in doctoral programs would increase access and inclusion for students in doctoral programs. This is what has been recommended by progressive disability resource center administrators in higher education settings (Mole, 2013). Inclusion of all students is supported when instructors incorporate UDL principles and techniques in their classes. Again, focusing on the academic environment supports the social model framework of disability, as well as an intersectional theory framework. Rather than emphasizing individual responsibility to find accommodations and modifications in locations outside the classroom or on strategies focused on specific identities or characteristics of individual students, administrators who promote the social model in higher education settings advocate for the inclusion of all students in classroom environments.

\section{Limitations}

Fein et al. (2003) suggested a "legend of cautions" when writing the results of a qualitative study. Readers should not assume that individuals with characteristics similar to the participants' cultural identities or disability types would have similar experiences to the participants. We cannot generalize findings in qualitative studies, and the hope is that readers realize that each participant's experiences were a sum of a variety of influences and processes.

\section{Conclusion}

This study was one of the first to document how doctoral students with disabilities who also have additional TUCGI experienced the successes and challenges of earning a doctoral degree, as they prepared to do research and teaching in their chosen fields. This study yielded multiple examples of doctoral-level students' struggles to receive accommodations and complete statistics coursework because of a lack of experience and knowledge of their instructors regarding working with students with disabilities or different learning styles. Studies that evaluate UDL techniques in graduatelevel coursework are needed to explore further how these techniques contribute to an inclusive, welcoming, collaborative environment for doctoral students. Additional studies that explore intersectionality theory as it relates to disability and academia are needed. Institutional policy that promotes accommodations for students with disabilities is insufficient. Disability awareness must be included in any institution-wide faculty and staff development training on the topic of diversity and inclusion, and UDL must be incorporated at the graduate level in academia. Additional research is needed to document the experiences of other students with significant disabilities at the graduate level in access and inclusion in statistics coursework. 


\section{References}

Aiston, S. J., \& Fo, C. K. (2021). The silence/ing of academic women. Gender and Education, 33(2), 138-155. https://doi.org/10.1080/09540253.2020.171 $\underline{6955}$

Aune, B. P., \& Kroeger, S. A. (1997). Career development of college students with disabilities: An interactional approach to defining the issues. Journal of College Student Development, 38(4), 344-356.

Azmitia, M., \& Thomas, V. (2015). Intersectionality and the development of self and identity. Emerging Trends in the Social and Behavioral Sciences: An Interdisciplinary, Searchable, and Linkable Resource, 1-9. https://doi.org/10.1002/9781118900772.etrds019 $\underline{3}$

Balcazar, F. E., Taylor-Ritzler, T., Dimpfl, S., PortilloPeña, N., Guzman, A., Schiff, R., \& Murvay, M. (2012). Improving the transition outcomes of low-income minority youth with disabilities. Exceptionality, 20(2), 114-132. https://doi.org/10.1080/09362835.2012.670 $\underline{599}$

Black, R. D., Weinberg, L. A., \& Brodwin, M. G. (2014). Universal design for instruction and learning: A pilot study of faculty instructional methods and attitudes related to students with disabilities in higher education. Exceptionality Education International, 24(1), 48-64. https://doi.org/10.5206/eei.v24i1.7710

Black, R. D., Weinberg, L. A., \& Brodwin, M. G. (2015). Universal design for learning and instruction: Perspectives of students with disabilities in higher education. Exceptionality Education International, 25(2), 1-16. https://doi.org/10.5206/eei.v25i2.7723

CAST. (2021). About universal design for learning. htt p://www.cast.org/our-work/about-udl.html

Charmaz, K. (2014). Constructing grounded theory. Sage.

Chronicle of Higher Education, Inc. (2021). Annual almanac issue, 2020/21. https://www.chronicle.com/p ackage/the-almanac-2020-2021

Collins, B. (2015). Reflections on doctoral supervision: Drawing from the experiences of students with additional learning needs in two universities. Teaching in Higher Education, 20(6), 587-600. http s://doi.org/10.1080/13562517.2015.1045859

Crenshaw, K. (1989). Demarginalizing the intersection of race and sex: A black feminist critique of antidiscrimination doctrine, feminist theory and antiracist politics. The University of Chicago Legal Forum, 140, 139-167. https://philpapers.org/rec/CRE DTI

Creswell, J. W., \& Poth, C. N. (2016). Qualitative inquiry and research design: Choosing among five approaches. Sage.

Damiani, M. L., \& Harbour, W. S. (2015). Being the wizard behind the curtain: Teaching experiences of graduate teaching assistants with disabilities at US universities. Innovative Higher Education, 40(5), 399-413. https://doi.org/10.1007/s10755-015-9326-7
Darolia, R., Koedel, C., Main, J. B., Ndashimye, J. F., \& Yan, J. (2020). High school course access and postsecondary STEM enrollment and attainment. Educational Evaluation and Policy Analysis, 42(1), 22-45. https://doi.org/10.3102/0162373719876923

Fein, M., Weis, L., Weseen, S., \& Wong, L. (2003). For whom? Qualitative research, representations, and social responsibilities. In N. K. Denzin \& Y. S. Lincoln (Eds.), Handbook of qualitative research (2nd ed., pp. 167-207). Sage.

Galanter, M., Dermatis, H., Post, S., \& Sampson, C. (2013). Spirituality-based recovery from drug addiction in the twelve-step fellowship of Narcotics Anonymous. Journal of Addiction Medicine, 7(3), 189-195. https://doi.org/10.1097/adm.0b013e31828a $\underline{0265}$

Glesne, C. (2015). Becoming qualitative researchers: An introduction (5th ed.). Pearson.

Godfrey, A. R., \& Loots, M. T. (2015). Advice from blind teachers on how to teach statistics to blind students. Journal of Statistics Education, 23(3), 1-28. https://do i.org/10.1080/10691898.2015.11889746

Happell, B., Wynaden, D., Tohotoa, J., Platania-Phung, C., Byrne, L., Martin, G., \& Harris, S. (2015). Mental health lived experience academics in tertiary education: The views of nurse academics. Nurse Education Today, 35(1), 113-117. https://doi.org/10.10 16/j.nedt.2014.07.006

Hatch, J. A. (2002). Doing qualitative research in education settings. State University of New York.

Hirschmann, N. (2012). Disability as a new frontier for feminist intersectionality research. Politics \& Gender, 8(3), 396-405. https://doi.org/10.1017/s1743923x120 $\underline{00384}$

Jairam, D., \& Kahl, D. H., Jr. (2012). Navigating the doctoral experience: The role of social support in successful degree completion. International Journal of Doctoral Studies, 7, 311-329. https://doi.org/10.2894 $\underline{5 / 1700}$

Kim, Y. M. (2013). Minorities in higher education: 26th status report. http://diversity.ucsc.edu/resources/imag es/ace report.pdf

King, J. E., \& Gomez, G. G. (2008). On the pathway to the presidency: Characteristics of higher education's senior leadership. American Council on Education.

Kutscher, E. L., \& Tuckwiller, E. D. (2019). Persistence in higher education for students with disabilities: A mixed systematic review. Journal of Diversity in Higher Education, 12(2), 136-155. https://doi.org/10.1037/dh e0000088

Liasidou, A. (2013). Intersectional understandings of disability and implications for a social justice reform agenda in education policy and practice. Disability and Society, 28(3), 299-312. https://doi.org/10.1080/0 9687599.2012.710012 
Marson, S. M., Harrington, C. F., \& Walls, A. (2013). Teaching introductory statistics to blind students. Teaching Statistics, 35(1), 21-25. https://doi.org/10.11 11/j.1467-9639.2012.00510.x

Martin, M. M., Goodboy, A. K., \& Johnson, Z. D. (2015). When professors bully graduate students: Effects on student interest, instructional dissent, and intentions to leave graduate education. Communication Education, 64(4), 438-454. https://doi.org/10.1080/03 634523.2015.1041995

Maxwell, J. A. (2012). Qualitative research design: An interactive approach (Vol. 41). Sage.

Mole, H. (2013). A US model for inclusion of disabled students in higher education settings: The social model of disability and Universal Design. Widening Participation and Lifelong Learning, 14(3), 62-86. http s://doi.org/10.5456/wpll.14.3.62

Montgomery, B. L. (2020). Academic leadership: Gatekeeping or groundskeeping? The Journal of Values-Based Leadership, 13(2), 1-15. https://doi.org/ 10.22543/0733.132.1316

Moore, C. L., Washington, A. L., Wang, N., Johnson, J., Davis, D., Eugene-Cross, K., Aref, F., Muhammad, A., Manyibe, E. O., \& Quinn, J. (2015). Disability, health, independent living, and rehabilitation research leaders from traditionally underrepresented racial and ethnic populations: Career development and success factors. Journal of Rehabilitation, 81(1), 19-33.

Museus, S. D., \& Griffin, K. A. (2011). Mapping the margins in higher education: On the promise of intersectionality frameworks in research and discourse. New Directions for Institutional Research, 2011(151), 5-13. https://doi.org/10.1002/ir.395

Nicholson, N. (2020). Rank and representation: A quantitative analysis of female representation within entry level faculty positions. Advances in Social Sciences Research Journal, 7(12), 202-209. https://do i.org/10.14738/assrj.712.9465

Oliver, M. (2013). The social model of disability: Thirty years on. Disability \& Society, 28(7), 1024-1026. http s://doi.org/10.1080/09687599.2013.818773

Paul, S. (2000). Students with disabilities in higher education: A review of the literature. College Student Journal, 34(2), 200-211.

Rao, K., Ok, M. W., \& Bryant, B. R. (2014). A review of research on universal design educational models. Remedial and Special Education, 35(3), 153-166. http s://doi.org/10.1177/0741932513518980

Rao, S. (2004). Faculty attitudes and students with disabilities in higher education: A literature review. College Student Journal, 38(2), 191-199.

Raue, K., \& Lewis, L. (2011). Students with disabilities at degree-granting postsecondary institutions. National Center for Education Statistics, U.S. Department of Education, Statistical Analysis Report, 18.

Rockinson-Szapkiw, A. J., \& Spaulding, L. S. (2014). Navigating the doctoral journey: A handbook of strategies for success. Rowman \& Littlefield.
Scarborough, A. A., \& McCrae, J. S. (2010). School-age special education outcomes of infants and toddlers investigated for maltreatment. Children and Youth Services Review, 32(1), 80-88. https://doi.org/10.1016/ j.childyouth.2009.07.015

Seidman, I. (2013). Interviewing as qualitative research: A guide for researchers in education and the social sciences. Teachers College Press.

Shaw, L. R., Chan, F., \& McMahon, B. T. (2012). Intersectionality and disability harassment: The interactive effects of disability, race, age, and gender. Rehabilitation Counseling Bulletin, 55(2), 82-91. http s://doi.org/10.1177/0034355211431167

Skiba, R., Poloni-Staudinger, L., Simmons, A., FegginsAzziz, R., \& Chung, C. (2005). Unproven links: Can poverty explain ethnic disproportionality in special education? The Journal of Special Education, 39, 130-144. https://doi.org/10.1177/0022466905039003 $\underline{0101}$

Smith, D. G., Tovar, E., \& García, H. A. (2012). Where are they? A multilens examination of the distribution of full-time faculty by institutional type, race/ ethnicity, gender, and citizenship. New Directions for Institutional Research, 2012, 5-26. https://doi.org/10.1 002/ir.20019

Test, D. W., Mazzotti, V. L., Mustian, A. L., Fowler, C. H., Kortering, L., \& Kohler, P. (2009). Evidence-based secondary transition predictors for improving postschool outcomes for students with disabilities. Career Development for Exceptional Individuals, 32(3), 160-181. https://doi.org/10.1177/0885728809346960

Torpey, E. (2019). High-wage occupations by typical entry-level education, 2017. U. S. Bureau of Labor Statistics. https://www.bls.gov/careeroutlook/2019/art icle/high-wage-occupations.htm

U.S. Bureau of Labor Statistics. (2021). Persons with a disability: Labor force characteristics 2020. https://ww w.bls.gov/news.release/pdf/disabl.pdf

Valentine, G. (2007). Theorizing and researching intersectionality: A challenge for feminist geography. The Professional Geographer, 59(1), 10-21. https://do i.org/10.1111/j.1467-9272.2007.00587.x

Van Manen, M. (2015). Researching lived experience: Human science for an action sensitive pedagogy. Left Coast Press.

Van Miegroet, H., Glass, C., Callister, R. R., \& Sullivan, K. (2019). Unclogging the pipeline: Advancement to full professor in academic STEM. Equality, Diversity and Inclusion: An International Journal, 38, 1-36. http s://doi.org/10.1108/edi-09-2017-0180

Warner, D. F., \& Brown, T. H. (2011). Understanding how race/ethnicity and gender define age-trajectories of disability: An intersectionality approach. Social Science \& Medicine, 72(8), 1236-1248. https://doi.org/ 10.1016/i.socscimed.2011.02.034

West, M., \& Curtis, J. W. (2006). AAUP Faculty Gender Equity Indicators 2006. American Association of University Professors. 
Yssel, N., Pak, N., \& Beilke, J. (2016). A door must be opened: Perceptions of students with disabilities in higher education. International Journal of Disability, Development and Education, 63(3), 384-394. https://d oi.org/10.1080/1034912x.2015.1123232 